ARTIFICIAL SATELLITES, Vol. 49, No. 1 - 2014
DOI: 10.2478/arsa-2014-0003

\title{
URBAN AREA GPS POSITIONING ACCURACY USING ASG-EUPOS POZGEO SERVICE AS A FUNCTION OF SESSION DURATION
}

\author{
Karol Dawidowicz, Grzegorz Krzan, Krzysztof Świątek \\ University of Warmia and Mazury in Olsztyn, Institute of Geodesy \\ e-mail: karol.dawidowicz@uwm.edu.pl
}

\begin{abstract}
GNSS observations carried out in a network of Continuously Operating Reference Station (CORS) are a complex systems which offer post-processing as well as corrections sent in realtime. In Poland, such a system has been in operation since June 2008, known as the Polish Active Geodetic Network (ASG-EUPOS).

Usually the measurements performed in real time characterized lower accuracy than static measurements. For users who demand the highest precision results the post-processing services are provided.

The paper presents an analysis of the position determination accuracy using ASG-EUPOS POZGEO service. It is well known that the final accuracy is e.g. the measuring conditions, time of observations or number of measured frequencies dependent. We processed 4 consecutive days of GPS data to determine how the accuracy of derived positional coordinates depends on the length of the observing session, the characteristics of horizon visibility on points and the used in post-processing observations (L1 or L1+L2). The POZGEO results show that horizontal accuracies of about 1-2 $\mathrm{cm}$ and vertical accuracies of $4 \mathrm{~cm}$ are achievable provided 0.5 hours dual frequency GPS data. The accuracy clearly decreases for point measured under conditions of strongly limited satellite availability.
\end{abstract}

Keywords: CORS, ASG-EUPOS, POZGEO, GNSS, static measurements.

\section{INTRODUCTION}

In the GNSS structure can be distinguished the so-called augmentation systems. These systems are classified into two groups: Space Based Augmentation Systems (SBAS) and Ground Based Augmentation Systems (GBAS). GBAS systems can be divided by the area of operation into: global (e.g. IGS - International GNSS Service), continental (e.g. EPN or AUSPOS), national or regional (e.g. ASG-EUPOS, CORS, SAPOS, SWEPOS). Another example of GBAS are so-called Local Area Augmentation Systems (LAAS), whose task is provide accuracy and integrity information in a local area, e.g. at an airport (Bosy et al., 2008; Figurski et al., 2009; Snay and Soler, 2009).

ASG-EUPOS is a Polish GNSS Ground Based Augmentation System (Bosy et al., 2008). The name ASG-EUPOS stands for Aktywna Sieć Geodezyjna - European Position Determination System. Its structure is divided into three basic segments: reference stations, management centre, user segment. These segments work together and provide precise realtime positioning and post-processing applications. The reference stations network currently (October 2013) consists of 101 Polish (77 with GPS and 24 with GPS/GLONASS module) and 22 foreign regularly distributed stations (www.asgeupos.pl). The mean distance between reference stations is in average $70 \mathrm{~km}$. Three real-time correction services and two post- 
processing services are currently available for users (Table 1). However it should be noted that at present $\mathrm{ASG}^{+}$project is in its final stage. The main objective of the project is to create supporting modules for currently operating in ASG-EUPOS system services, create new system services and improve the quality of positioning (Figurski et al., 2011).

Table 1. ASG-EUPOS services (www.asgeupos.pl)

\begin{tabular}{|c|c|c|c|c|c|}
\hline $\begin{array}{c}\text { SERVICE } \\
\text { GROUP }\end{array}$ & $\begin{array}{c}\text { SERVICE } \\
\text { NAME }\end{array}$ & $\begin{array}{c}\text { SURVEY } \\
\text { METHOD }\end{array}$ & $\begin{array}{c}\text { DATA } \\
\text { ACCESS }\end{array}$ & $\begin{array}{c}\text { ESTIMATED } \\
\text { PRECISION }\end{array}$ & $\begin{array}{c}\text { MINIMUM HARDWARE } \\
\text { REQUIREMENTS }\end{array}$ \\
\hline $\begin{array}{c}\text { Real-time } \\
\text { services }\end{array}$ & NAWGEO & $\begin{array}{c}\text { kinematic } \\
\text { RTK }\end{array}$ & $\begin{array}{c}\text { GSM } / \\
\text { Internet }\end{array}$ & $\begin{array}{c}0.03 \mathrm{~m} \text { (horiz) } \\
0.05 \mathrm{~m} \text { (vert.) }\end{array}$ & $\begin{array}{c}\text { L1/L2 GNSS RTK receiver, } \\
\text { communication module }\end{array}$ \\
\cline { 2 - 3 } & KODGIS & $\begin{array}{c}\text { kinematic } \\
\text { DGPS }\end{array}$ & $0.2-0.5 \mathrm{~m}$ & $\begin{array}{c}\text { L1 DGNSS receiver, } \\
\text { communication module }\end{array}$ \\
\cline { 2 - 3 } $\begin{array}{c}\text { Post- } \\
\text { processing } \\
\text { services }\end{array}$ & POZGIS & static & Internet & $0.01-0.10 \mathrm{~m}$ & L1 GNSS receiver \\
\cline { 2 - 3 } & POZGEO D & $\begin{array}{c}\text { static / } \\
\text { kinematic }\end{array}$ & & & \\
\hline
\end{tabular}

Single base station RTK positioning is a technique that allows accurate position determination in real time through differencing similar errors and biases at both ends of a baseline. This concept involves a reference receiver which sends its position and satellite observations to the rover via some sort of data communication. Additionally, both the reference and the rover must observe the same set of satellites. The rover combines these reference station observations with its own observations to compute position. One significant drawback of single base RTK approach is that the maximum distance between the reference and the rover receiver must not exceed 10 to $20 \mathrm{~km}$ in order to be able to rapidly and reliably resolve the carrier phase ambiguities (Wanninger, 2004; Wegner and Wanninger, 2005).

Network-based Real Time Kinematic (NRTK) positioning overcomes such drawbacks and increases accuracy by accurately modeling the distance dependent errors at the rover position. In order to increase the distance from the reference station for which it is possible to achieve a centimeter level solution, various methods were developed based on the use of networks of GNSS reference stations (Erhu et al., 2006; Euler et al., 2001; Wanninger 1997).

NAWGEO is a fundamental ASG-EUPOS service which provides corrections for realtime RTK measuring. It provides high accuracy positioning for the measurement of kinematic and static objects. Other services (KODGIS and NAWGIS) are intended for users who do not require such high accuracy. Using the NAWGEO service, a user has the possibility to take measurements in Single Base Station mode, or chose one of two types of RTK corrections (Masterter and Auxiliary Concept or Virtual Reference Station).

A review of the real time services accuracy can be found e.g. in: Bakuła and Przestrzelski, 2013; Dawidowicz, 2012; Edwards et al., 2010; Hadaś and Bosy, 2009; Kowalczyk and Tymoszczuk, 2012; Kudrys and Krzyżek, 2011; Wiśniewski et al., 2013.

The POZGEO-D service is meant for users who utilize their own software to process GNSS observations. In this approach, user downloads observation from ASG-EUPOS reference stations for their own processing. Using the POZGEO-D service makes possible to obtain higher accuracy from shorter observational sessions, although, it requires some knowledge of GNSS observation processing.

Using the POZGEO service, a user sends observation files in order to receive automatically calculated coordinates of the measured points. The result are available via the ASG-EUPOS website. Post-processing of the uploaded observations and determination of the point's coordinates are made independently in reference to the six nearest system station. Because of the relatively long distances between stations $(\sim 70 \mathrm{~km})$ and the automation of the calculation process, obtaining high accuracy requires long observation sessions (Eckle et al., 2001; El- 
Mowafy, 2011; Kadaj, 2010). The final accuracy also depends on e.g. the measuring conditions, time of observations or number of observed frequencies.

The paper presents an analysis of the position determination accuracy using ASG-EUPOS POZGEO service. We processed 4 consecutive days of GPS data using POZGEO service to determine how the position accuracy depends on the length of the observing session, the characteristics of horizon visibility on points and the used in post-processing observations (L1 or L1+L2). For analysis three points with different characteristics of horizon visibility, divided by $0.5,1,2,3,4$ and 6 hour observation sessions were chosen.

\section{METHODOLOGY OF STUDIES}

The paper presents an analysis of the accuracy of the position determination using singlereceiver GNSS measurements done under conditions of limited satellite availability, processed using ASG-EUPOS POZGEO service. Four days of static measurements were used to evaluate the accuracy of position determination in POZGEO services. The location of the test area and nearest ASG-EUPOS stations are presented in Figure 1.

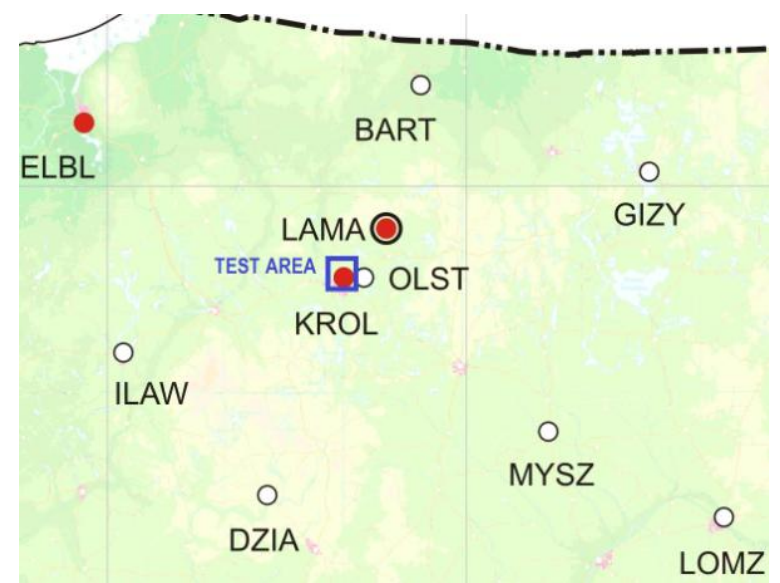

Fig. 1. Location of the test area and the nearest ASG-EUPOS stations (map: www.asgeupos.pl)

To analysis three points were selected. As a point A the ASG-EUPOS reference station KROL in Olsztyn was adopted, assuming that this is the point with optimal observing conditions without any obstructions. Points B and C are marked in an urban area, where occurring trees or buildings limiting the number of observed satellites and increases the risk of multipath (Table 2).

Table 2. Test points

\begin{tabular}{|c|c|c|c|}
\hline Point name & A & B \\
\hline Localization & & \\
\hline Receiver type & $\begin{array}{c}\text { JAVAD TRE_G3TH } \\
\text { SIGMA }\end{array}$ & TOPCON HiperPRO & TOPCON HiperPRO \\
\hline Antenna type & $\begin{array}{c}\text { JAV_GRANT-G3T } \\
\text { JAVC }\end{array}$ & TPSHIPER_PLUS & TPSHIPER_PLUS \\
\hline
\end{tabular}


Measurements were carried out five days (from 20 to 24 November 2012). Sessions started and ended at 17:00 thus finally we obtained four 24-hour measurement data. The GNSS parameters we adopted for measurement sessions: minimum height of satellites above the horizon $10^{\circ}$, measurement interval $1 \mathrm{~s}$. Using two frequency receivers allowed us to divide observations into 2 variants depending on the observed signals: L1+L2 observations and L1only observations.

24-hour data were subdivided into 6 time variants $(0.5 \mathrm{~h}, 1 \mathrm{~h}, 2 \mathrm{~h}, 3 \mathrm{~h}, 4 \mathrm{~h}$ and $6 \mathrm{~h})$ using TEQC software. This resulted in 192 half-hour, 96 hour, 48 two-hour, 32 three-hour, 24 four-hour and 16 six-hour sessions for each measurement point. Prepared in this way observations were send to ASG-EUPOS POZGEO service. Post-processing was performed using the most precise IGS Final orbit and satellite clock corrections (http://www.asgeupos.pl).

In the first variant $(\mathrm{L} 1+\mathrm{L} 2)$ observations were processed in reference to the six nearest system station, in the second (L1) - in reference to the four nearest system station (Fig. 1).

Some characteristic of selected to measurements points are presented below. Figure 2 present the visibility of the horizon from points $\mathrm{A}, \mathrm{B}$ and $\mathrm{C}$.

a)

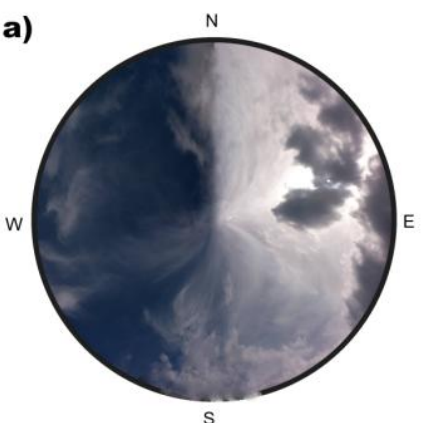

b)

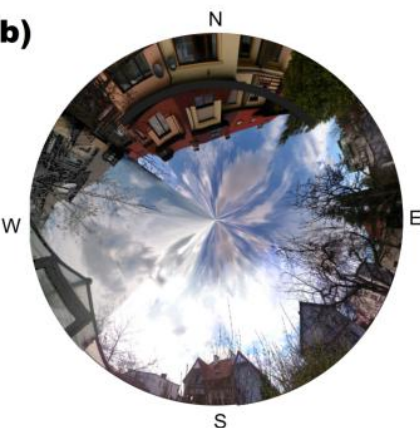

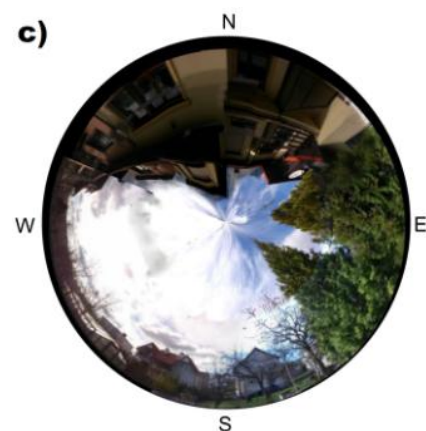

Fig. 2. Obstructions on the measured points: a) A point, b) B point, c) C point

As a consequence, satellites visibility (Fig. 3) and PDOP coefficient (Fig. 4) noticeably differ on measured points during the same time.

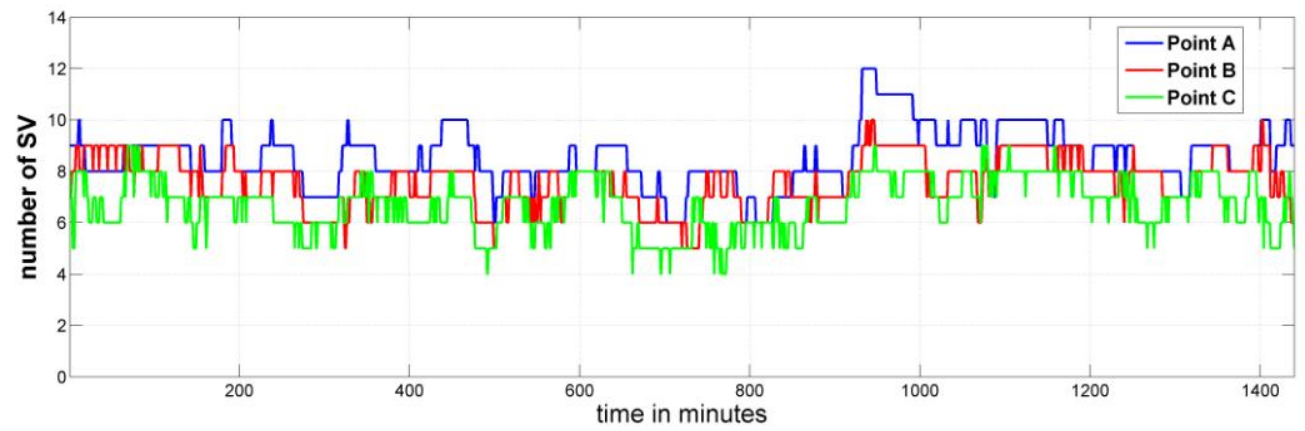

Fig. 3. Satellites visibility on measured points

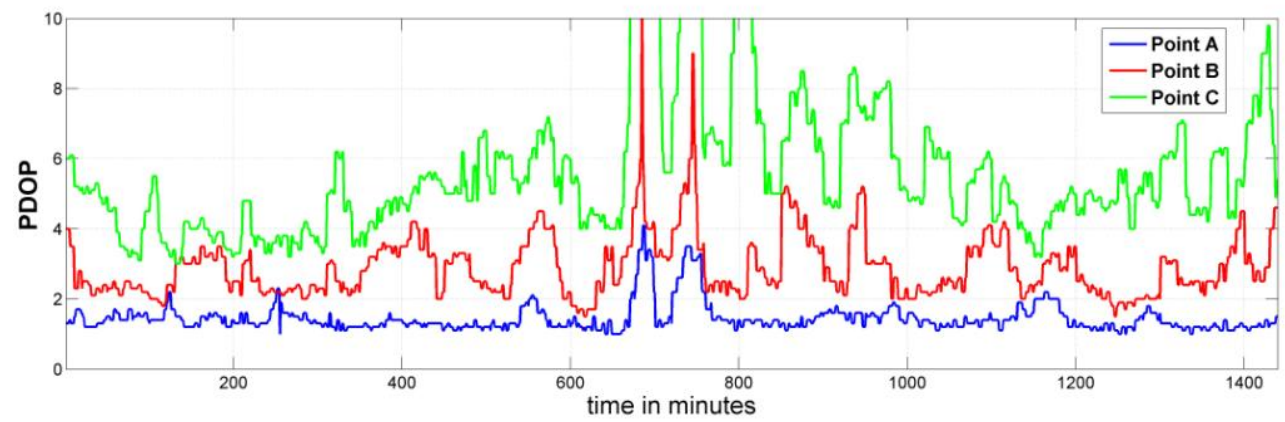

Fig. 4. PDOP coefficient on measured points 
Analyzing Fig. 3 it is visible that the number of the satellites observed at measured points differ. The average number of satellites observed at points $\mathrm{A}, \mathrm{B}$ and $\mathrm{C}$ was $8,7,6$ respectively.

The effect of terrain obstacles on the PDOP coefficient can be seen in Fig. 4. The worst situation, as expected, occurred on point $\mathrm{C}$, where in some periods PDOP coefficient exceeds 10 .

As mentioned early in the POZGEO service a user receive automatically calculated coordinates of the measured points and has only little influence on the choice of processing options (e.g. duration of session, measurements interval, post-processing observations: L1 or L1+L2). Antenna calibration model, for example, is beyond possibility of selection. Thus in our analysis we used standard ASG-EUPOS antennas calibration model (absolute antennas calibration model).

\section{RESULTS AND ANALYSIS}

The results of obtained positioning accuracy based on POZGEO services are presented in this section. The following figures and tables are presented to provide some insight into the accuracy of the estimated solutions from performed processing variants. Figures 5-7 show the $\mathrm{x}_{2000}, \mathrm{y}_{2000}$ and $\mathrm{h}_{\text {GRS'80 }}$ distribution of differences between estimated positions of the "unknown" points and their corresponding "true" position. The average position from the four 24-h L1+L2 sessions was adopted as the 'true' position. It should be noted that the differences between 24-h session results were within $0.4 \mathrm{~cm}$ for $\mathrm{x}_{2000}$ and $\mathrm{y}_{2000}$ coordinates and within 0.8 $\mathrm{cm}$ for $\mathrm{h}_{\mathrm{GRS}} 80$.

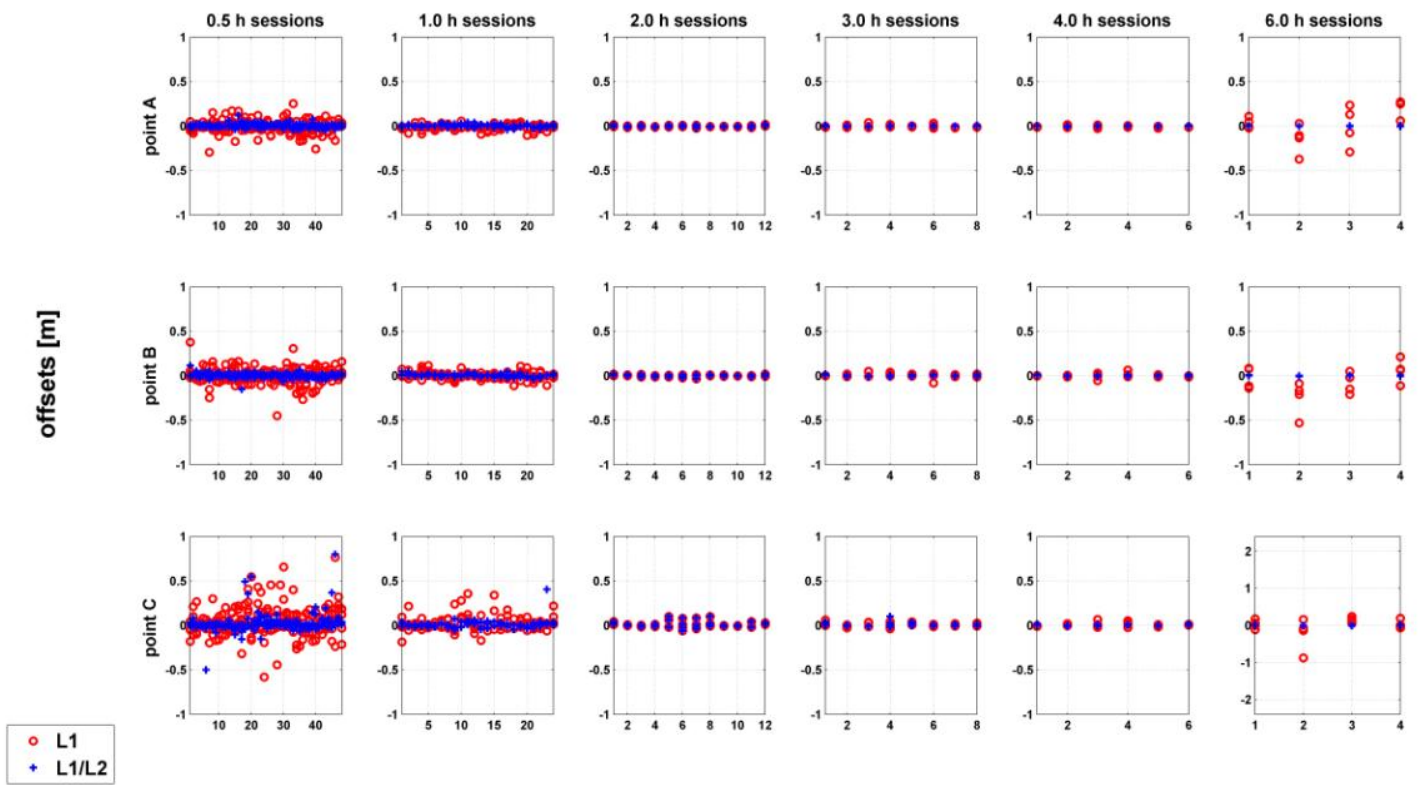

Fig. 5. $\mathrm{x}_{2000}$ offsets between estimated positions and "true" position 

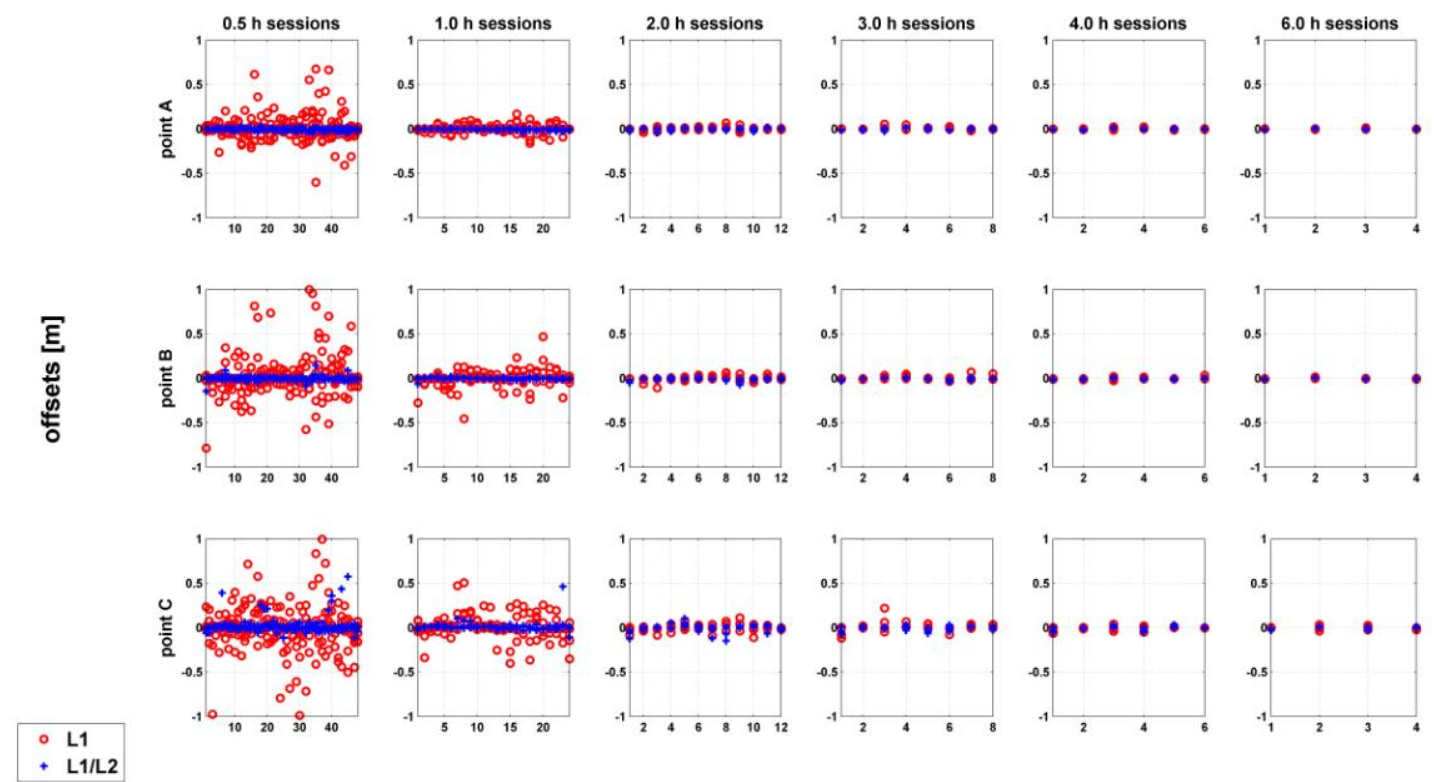

Fig. 6. $\mathrm{y}_{2000}$ offsets between estimated positions and "true" position
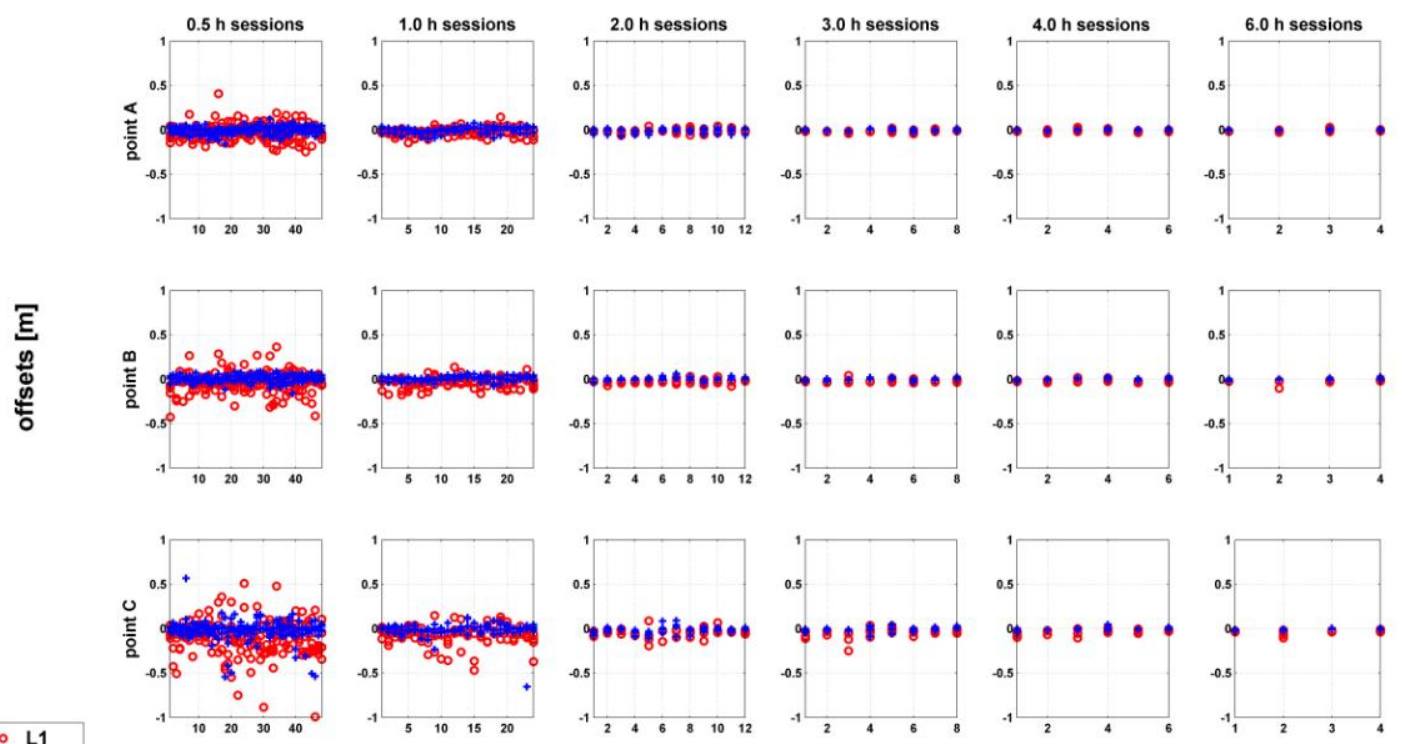

+ L1/L2

Fig. 7. $\mathrm{h}_{\mathrm{GRS} ' 80}$ offsets between estimated positions and "true" position

In Figures 5-7, the maximum offsets from 24-hour means are presented. It is visible that the largest differences occurred for short sessions and points where observations were done under conditions of limited satellite availability. Generally, processing one hour or longer sessions using ASG-EUPOS POZGEO service (L1+L2 processing variant), in areas with not a very high degree of obstructions, guarantees that $\mathrm{x}_{2000}$ and $\mathrm{y}_{2000}$ offsets will be below $0.05 \mathrm{~m}$. For point $\mathrm{A}$, where the best measurement conditions were, even 0.5 hour sessions were sufficient to keep this condition. For ellipsoidal height, as expected, noticeable worse results were achieved. Two hours or longer sessions were needed to guarantees that offsets will be below $0.05 \mathrm{~m}$. Analyzing L1 variant results it is visible that offsets are significantly larger comparing to $\mathrm{L} 1+\mathrm{L} 2$ variant, especially for 0.5 and 1.0 hour sessions and unexpected for 6.0 hours sessions ( $\mathrm{x}_{2000}$ coordinate). These last offsets are difficult to explain. 
Figures 8-9 presents RMS errors as a function of session duration and observing conditions at the point. The positioning RMS errors are calculated from the differences between the 'true' $\mathrm{x}_{2000}, \mathrm{y}_{2000}$ and $\mathrm{h}_{\mathrm{GRS}^{\prime} 80}$ coordinates with the estimated values.
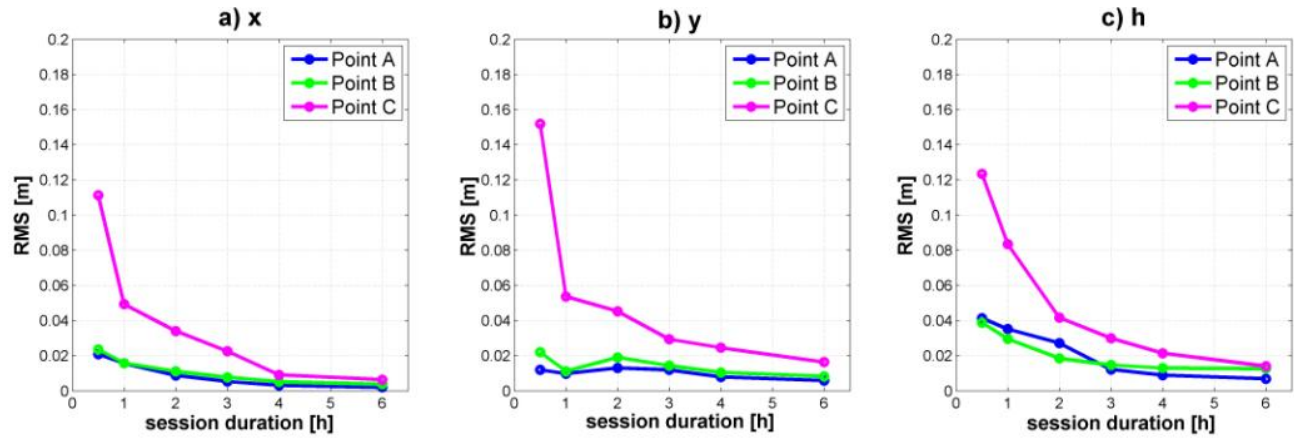

Fig. 8. POZGEO RMS positioning statistics for L1+L2 processing variant
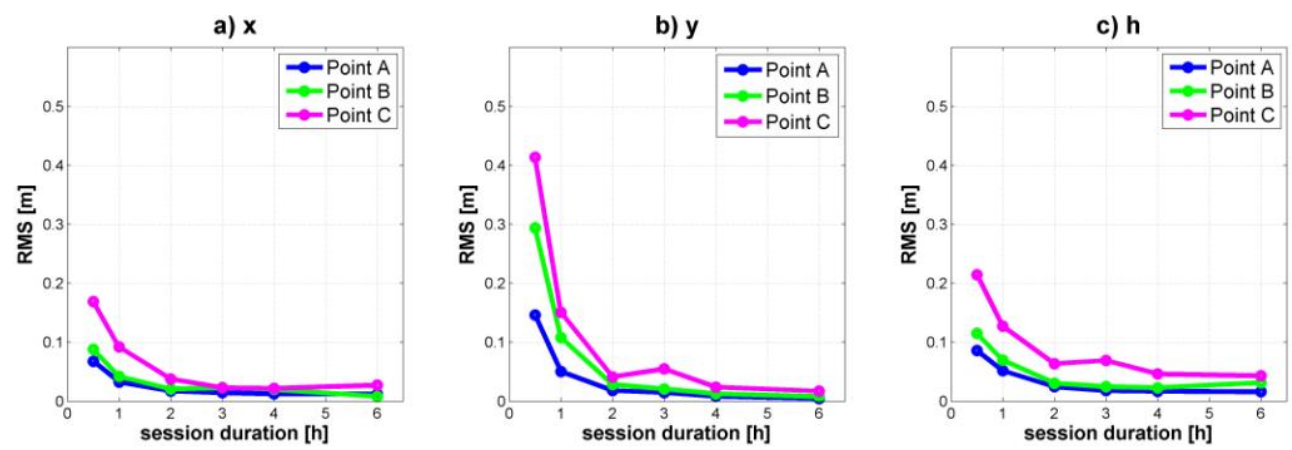

Fig. 9. POZGEO RMS positioning statistics for L1 processing variant

In analyzing the results presented in Figures 8-9, it is clear that both the length of sessions and observing conditions significantly affect the position determination accuracy. Point $\mathrm{C}$ is characterized by the largest RMS errors. The impact of obstacles is especially visible in the case of processing short L1+L2 observation sessions ( 0.5 and 1.0 hour). RMS error obtained for point $\mathrm{C}$ is significantly larger compared to points $\mathrm{A}$ and $\mathrm{B}$. For longer sessions, RMS differences between the selected measurements points was clearly reduced. For L1 postprocessing variant results it is visible that impact of obstacles is not as crucial as for $\mathrm{L} 1+\mathrm{L} 2$ variant. More important is length of the session.

The mean positioning accuracy from ETRS'89 Cartesian coordinates were also calculated. For calculation, as previously, the average coordinates from the four $24-\mathrm{h} \mathrm{L} 1+\mathrm{L} 2$ sessions was adopted as the 'true'. The mean 3D positioning errors, depending on satellites visibility on points, respectively regrouped, in Fig. 10 were presented.
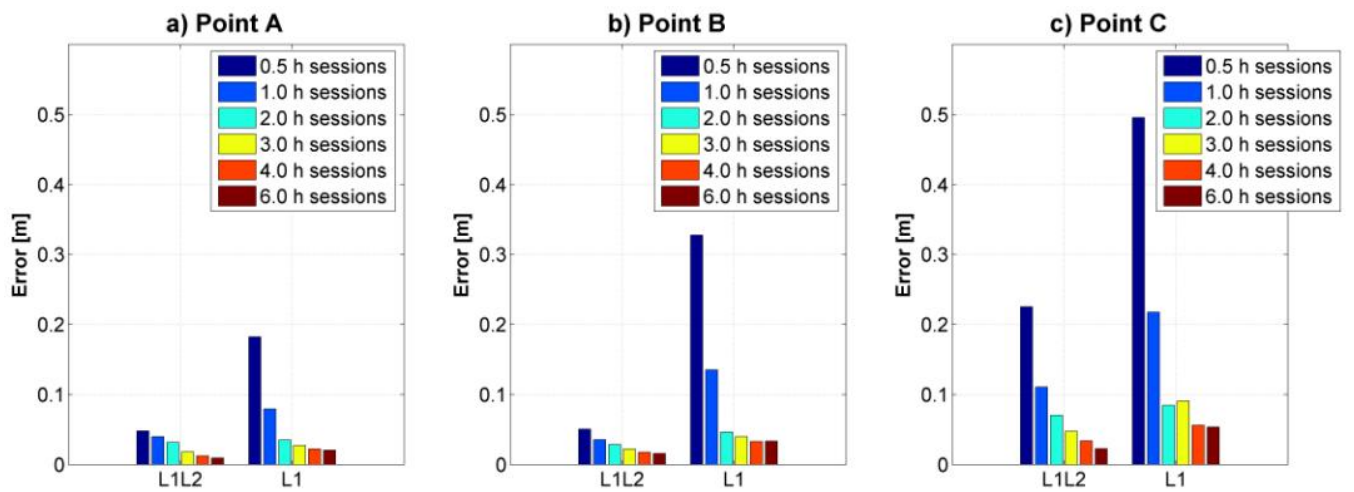

Fig. 10. Mean 3D-positioning accuracy comparison 
Analyzing the results presented in Fig. 10 it is visible that mean 3D positioning error visible increases when measuring conditions getting worse. However, larger impact on the accuracy has the measurement session duration and, first of all, used in post-processing type of observations ( $\mathrm{L} 1$ or $\mathrm{L} 1+\mathrm{L} 2)$.

In Table 3, the values of mean 3D positioning error were presented. The results obtained using the L1 and L1+L2 frequencies are compared. Additionally, those variants for which an improvement of the accuracy was not achieved in bold were marked.

Table 3. Mean 3D positioning error comparison

\begin{tabular}{|c|c|c|c|c|c|c|}
\hline \multirow{2}{*}{$\begin{array}{c}\text { Session } \\
\text { duration } \\
{[\mathrm{h}]}\end{array}$} & \multicolumn{6}{|c|}{ Mean 3D positioning error [m] } \\
\cline { 2 - 7 } & L1 & L1+L2 & L1 & L1+L2 & L1 & L1+L2 \\
\hline 0.5 & 0.182 & 0.048 & 0.328 & 0.050 & 0.335 & 0.225 \\
\hline 1.0 & 0.079 & 0.040 & 0.135 & 0.035 & 0.144 & 0.111 \\
\hline 2.0 & 0.035 & 0.032 & 0.046 & 0.029 & $\mathbf{0 . 0 5 5}$ & $\mathbf{0 . 0 7 0}$ \\
\hline 3.0 & 0.027 & 0.018 & 0.040 & 0.022 & 0.053 & 0.048 \\
\hline 4.0 & 0.022 & 0.012 & 0.033 & 0.017 & 0.037 & 0.034 \\
\hline 6.0 & 0.020 & 0.009 & 0.033 & 0.016 & 0.036 & 0.023 \\
\hline
\end{tabular}

From the results presented in Table 3, it can be seen, as expected, that improvement of the positioning accuracy is obvious for most of the position results when L1 and L1+L2 solutions are compared. The only exception are the results obtained using ASG-EUPOS service from 2hour sessions on point $\mathrm{C}$ (the worst measurements conditions).

Finally it should be noted that occasionally in the ASG-EUPOS POZGEO service, instead of results we obtained a message that the calculations failed due to exceeding the precision requirements limit after adjusting. Table 4 presents a number of solutions obtained using the POZGEO service for 0.5 and 1.0-hour sessions. For two-hour and longer sessions 100\% solutions were obtained.

Table 4. Number of solutions obtained using the POZGEO service

\begin{tabular}{|c|c|c|c|c|c|c|}
\hline \multirow{2}{*}{$\begin{array}{c}\text { Session } \\
\text { duration } \\
\text { [min.] }\end{array}$} & \multicolumn{4}{|c|}{ The number of obtained solutions [\%] } \\
\cline { 2 - 7 } & L1+L2 & L1 & L1+L2 & L1 & L1+L2 & L1 \\
\hline 30 & 100 & 100 & 98 & 99 & 88 & 99 \\
\hline 60 & 100 & 100 & 100 & 100 & 97 & 100 \\
\hline
\end{tabular}

As expected, the most of the cases where the calculations failed due to exceeding the precision requirements limit occurred on point $\mathrm{C}$ (the worst measurements conditions). For 0.5 hour session in $\mathrm{L} 1+\mathrm{L} 2$ variant $12 \%$ calculations failed.

\section{CONCLUSIONS}

In this paper, we analyzed the accuracy of the position determination using single-receiver GNSS measurements done on points with different observing conditions. The analysis was based on four days of data from three GNSS stations. To process the observations, ASGEUPOS POZGEO services were chosen. The study was done from an end-user point-ofview: the measurements and procedures were the same as any other surveyor would have done.

The results show, as expected that both the length of sessions and observing conditions significantly affect the position determination accuracy. The impact of obstacles is especially visible in the case of processing short L1+L2 observation sessions. For longer sessions, the influence of observing conditions on the accuracy was clearly reduced. 
Single frequency POZGEO results are characterized by very low accuracy. The worse results for the y coordinate were obtained. When observations were performed at one frequency in 30 minutes sessions, the accuracy of $0.10-0.20 \mathrm{~m}$ was achieved for the $\mathrm{x}$ and $\mathrm{h}$ coordinates and $0.15-0.40 \mathrm{~m}$ for the y component (RMS). The values improved clearly when a session duration became longer and also depend on observing conditions.

In analyzing the mean 3D positioning accuracy in the POZGEO service (comparison of L1 and L1+L2 solutions), an improvement is clear for most of the position results. The only exception were the results obtained from the 2-hour sessions at point $\mathrm{C}$ (where the worst measurements conditions occurred).

Generally it can be concluded that the horizontal accuracies (RMS) of about $1-2 \mathrm{~cm}$ and vertical accuracies of $4 \mathrm{~cm}$ are achievable in POZGEO service provided 0.5 hours low multipath dual frequency GNSS data. For such sort sessions the accuracy clearly decreases for point measured under conditions of strongly limited satellite availability or when L1-only observations are available.

It can be expected that in the near future, when $\mathrm{ASG}+$ project results will be implemented and when all ASG-EUPOS stations will be equipped in multi-GNSS receivers, significant improve of the quality of POZGEO positioning occurs.

\section{REFERENCES}

Bakuła M., Przestrzelski P. (2013): Technologia wiarygodnego pozycjonowania RTK GPS/GLONASS, Przegląd Geodezyjny, No 7: 3-9.

Bosy J., Oruba A., Graszka W., Leończyk M., Ryczywolski M., (2008): ASG-EUPOS densification of EUREF Permanent Network on the territory of Poland. Reports on Geodesy, No. 2 (85): 105-112.

Dawidowicz K., (2012): GNSS satellite leveling using the ASG-EUPOS system services. Technical Sciences, No. 15(1): 35-48.

Eckle M. C., Snay R. A., Soler T., Cline M. W., Mader G. L. (2001): Accuracy of GPSderived relative positions as a function of interstation distance and observing-session duration. Journal of Geodesy, Vol. 75: 633-640.

Edwards S. J., Clarke P. J., Penna N. T., Goebell S. (2010): An examination of network RTK GPS services in Great Britain. Survey Review, No. 42(316): 107-121.

El-Mowafy A. (2011): Analysis of web-based GNSS post-processing services for static and kinematic positioning using short data spans. Survey Review, No. 43(323): 535-549.

Erhu W., Hua Ch., Zhiguo A. (2006): VRS Virtual Observations Generation Algorithm. Journal of Global Positioning Systems, Vol. 5, No. 1-2: 76-81.

Euler H.J., Keenan C.R., Zebhauser B.E. Wübbena G. (2001): Study of a Simplified Approach in Utilizing Information from Permanent Reference Station Arrays. Proc. ION GPS 2001, Salt Lake City.

Figurski M., Kamiński P., Kroszyński K., Szafranek K. (2009): ASG-EUPOS monitoring with referemce to EPN. Artificial satellites, Vol. 44, no. 3: 85-04.

Figurski M., Bogusz J., Bosy J., Kontny B., Krankowski A., Wielgosz P.(2011): „ASG+”: project for improving Polish multifunctional precise satellite positioning system. Reports on Geodesy, No 2(91): 51-58.

Hadaś J., Bosy J. (2009): Niwelacja satelitarna GNSS z wykorzystaniem serwisu NAWGEO system ASG-EUPOS. Acta Sci. Pol., Geodesia et Descripto Terrarum, No. 8(2): 53-66. 
Kadaj R. (2010): Application of Schreiber's type difference observation system for elaboration of a session of static GPS measurements; Biuletyn Wojskowej Akademi Technicznej, Vol. LIX, No. 2 (658): 85-106.

Kowalczyk K., Tymoszczyk T. (2012): Opracowanie trójwymiarowego modelu dna stawu w aplikacji SURFER przy użyciu danych z pomiaru GPS RTK. Zeszyty Naukowe Politechniki Rzeszowskie, No. 283(59): 197-206.

Kudrys J., Krzyżek R. (2011): Analysis of Coordinates Time Series Obtained Using the NAWGEO Service of the ASG-EUPOS System. Geomatics and Environmental Engineering, Vol. 5 No. 4: 39-47.

Snay R. A., Soler T. (2008): Continuously Operating Reference Station (CORS): History, Applications, and Future Enhancements. Journal of Surveying Engineering, Vol. 134, No. 4: 95-104.

Wanninger L. (1997): Real-Time Differential GPS-Error Modeling in regional Reference Stations Networks. Proc. IAG Symp 118, Rio de Janerio, 86-92.

Wanninger L. (2004): Introduction to Network RTK. Paper presented at the International Association to Geodesy meeting, Working Group 4.5.1: Network RTK, Dresden, Germany, available at: http://www.wasoft.de/e/iagwg451/intro/introduction.html.

Wegener V. and Wanninger L. (2005): Communication Options for Network RTK. International Association of Geodesy. Working Group 4.5.1: Network RTK. Available at: http://www.network-rtk.info/wegener/communication.html.

WiśniewskiB., Bruniecki K., Moszyński M. (2013): Evaluation of RTKLIB's Positioning Accuracy Using low-cost GNSS Receiver and ASG-EUPOS. The International Journal on Marine Navigation and Safety of Sea Transportation Vol 7, No 1: 79-85.

Received: 2013-10-09,

Reviewed: 2013-12-09, by Z. Siejka,

Accepted: 2013-12-09. 